Article

\title{
Purification and Biochemical Characterization of TsMS 3 and TsMS 4: Neuropeptide-Degrading Metallopeptidases in the Tityus serrulatus Venom
}

\author{
Daniela Cajado-Carvalho ${ }^{1, *(1)}$, Cristiane Castilho Fernandes da Silva ${ }^{1}$, \\ Roberto Tadashi Kodama ${ }^{1}$, Douglas Oscar Ceolin Mariano ${ }^{2}$ (D) Daniel Carvalho Pimenta ${ }^{2}$ (D), \\ Bruno Duzzi ${ }^{1}$, Alexandre Kazuo Kuniyoshi ${ }^{1}$ and Fernanda Vieira Portaro ${ }^{1, * \mathbb{D}}$ \\ 1 Immunochemistry Laboratory, Butantan Institute, São Paulo SP 05503-900, Brazil; \\ cristiane.silva@butantan.gov.br (C.C.F.d.S.); roberto.kodama@butantan.gov.br (R.T.K.); \\ bruno.duzzi@butantan.gov.br (B.D.); alexandre.kuniyoshi@butantan.gov.br (A.K.K.) \\ 2 Biochemistry and Biophysics Laboratory, Butantan Institute, São Paulo SP 05503-900, Brazil; \\ douglas.mariano@butantan.gov.br (D.O.C.M.); dcpimenta@butantan.gov.br (D.C.P.) \\ * Correspondence: daniela.carvalho@butantan.gov.br (D.C.-C.); fernanda.portaro@butantan.gov.br (F.V.P.)
}

Received: 1 March 2019; Accepted: 28 March 2019; Published: 31 March 2019

\begin{abstract}
Although omics studies have indicated presence of proteases on the Tityus serrulatus venom (TsV), little is known about the function of these molecules. The TsV contains metalloproteases that cleave a series of human neuropeptides, including the dynorphin A (1-13) and the members of neuropeptide $\mathrm{Y}$ family. Aiming to isolate the proteases responsible for this activity, the metalloserrulase 3 and 4 (TsMS 3 and TsMS 4) were purified after two chromatographic steps and identified by mass spectrometry analysis. The biochemical parameters $(\mathrm{pH}$, temperature and cation effects) were determined for both proteases, and the catalytic parameters $\left(K_{m}, \mathrm{k}_{c a t}\right.$, cleavage sites $)$ of TsMS 4 over fluorescent substrate were obtained. The metalloserrulases have a high preference for cleaving neuropeptides but presented different primary specificities. For example, the Leu-enkephalin released from dynorphin A (1-13) hydrolysis was exclusively performed by TsMS 3. Neutralization assays using Butantan Institute antivenoms show that both metalloserrulases were well blocked. Although TsMS 3 and TsMS 4 were previously described through cDNA library studies using the venom gland, this is the first time that both these toxins were purified. Thus, this study represents a step further in understanding the mechanism of scorpion venom metalloproteases, which may act as possible neuropeptidases in the envenomation process.
\end{abstract}

Keywords: Tityus serrulatus; metalloserrulases; proteases; purification; biochemical characterization; neuropeptides

Key Contribution: Two new metalloproteinases were isolated from the Tityus serrulatus venom and were biochemically characterized. The two proteases cleave neuropeptides in vitro; but with different hydrolysis rates and distinct primary specificities.

\section{Introduction}

Scorpion accidents have been the main cause of human envenomation by animals in Brazil since 2007 [1]. These occurrences are associated with the easy adaptation of scorpions to urban centers, which offer shelter, food availability, and the absence of natural predators [2]. In particular, the Tityus serrulatus is considered the main Brazilian species of medical importance, as it is responsible for a greater number of severe envenomation cases when compared with other scorpion species $[3,4]$. Accidents are especially lethal when they occur with children under five years of age and the elderly, 
becoming a relevant public health problem in Brazil. Thus, there is interest from the scientific community regarding the study of this species and its venom components.

Animal venoms are a mixture of toxins with diverse biological effects, which could be used as a source for bioactive molecules. Among these, peptidases are often found in animal venoms, especially in snakes [5,6]. For example, snake venoms from the Viperidae family are known to be comprised of metallo and serinoproteases [7]. Proteolytic enzymes are the main toxins in most of these venoms and accidents symptoms are frequently associated to the activities of these molecules, mainly severe haemostatic disturbances, like consumptive coagulopathy and local or systemic hemorrhage [8,9].

Scorpion venoms, on the other hand, are better known and characterized by their neurotoxic activity [10]. However, little is known about their proteolytic components and their role during the envenomation process. This could be partially explained by the lack of information about the effects of scorpion venom peptidases, or even due to the difficulty of obtaining ideal amounts of these venoms for the isolation of such molecules. Fortunately, "omics" techniques (proteomic and transcriptomic) have recently helped the study of peptidases in these arachnids [11-14]. Notably, transcriptomic studies have shown that proteases are the most abundant transcripts in the Brazilian scorpions from the Tityus genus, representing $48 \%, 38 \%$ and $33 \%$ of the venom glands transcripts of Tityus obscurus, T. bahiensis and T. serrulatus respectively $[14,15]$. Also, cDNA analysis of the T. serrulatus venom gland using a primer for the M13 metalloproteinase family, revealed the presence of clones of ten peptidases, which were named "metalloserrulases". Nine putative sequences (TsMS 1 to 9) have the signature of the metzincins family, a group of metalloproteases including matrix metalloproteinases and ADAM proteases. Differently, the last one, TsMS 10, is classified as a member of the gluzincin family, group which includes enzymes like the angiotensin I-converting enzyme, the endothelin I-converting enzyme and the neprilysin [16]. These classifications are based on a conserved sequence of catalytic sites of zinc metallopeptidases, since metzincins have an extended zinc-binding sequence (HEXXHXXGXXH), in addition to a Met-turn methionine that helps to coordinate the metal ion; and gluzincins which have a shorter catalytic site (HEXXH), in addition to a glutamate helix below the active-site helix [17]. Finally, metalloserrulases 1 and 2 (TsMS 1 and TsMS 2) showed the highest percentage of similarity with the primary structure of antarease, which could indicate similar activities; while metalloserrulase 4 (TsMS 4) had the lowest similarity with this scorpion venom protease, suggesting diversity of functions [16].

Antarease was the first protease purified from the Tityus serrulatus venom (TsV), which was characterized by the hydrolysis of proteins involved in the transport of vesicle to the cell membrane, the VAMPs [18]. In addition, Zornetta et al. (2017) showed that the active recombinant antarease caused neuroparalysis at the neuromuscular junction of rats and flies (D. melanogaster) by the cleavage of proteins on the surface of the pre-synaptic membrane, thus preventing neuroexocytosis. Moreover, this observation was attributed to proteolytic activity, since the inactive enzymatic mutant protein did not achieve the same effect [19]. Ortiz et al. (2014) showed, by transcriptome analysis, the existence of antarease molecules in venoms of other species of scorpions from Central America (T. fasciolatus, T. pachyurus), North America (Centruroides noxius) and Asia (Mesobuthus), indicating conservation of these enzymes in the Buthidae scorpion family, regardless of their geographic origin [20]. The second metallopeptidase purified and characterized from $\mathrm{TsV}$ was an Angiotensin-Converting Enzyme-like (ACE) peptidase [21], and its ability to release angiotensin II from angiotensin I might contribute to hypertension, which is a symptom that is commonly described on patients envenomed by the T. serrulatus scorpion. Interestingly, the ACE-like sequence was also found in transcripts from scorpion venom glands of the Buthidae family $[11,14,15,21]$, which suggest conservation of this molecule on scorpion venoms during their evolution.

Besides the transcriptomic analyzes, peptidomic studies have detected the activity of endopeptidases and exopeptidases over endogenous venom-peptides, being considered important post-translational agents for the formation of toxins [22]. 
Regarding functional activities, studies using the total venom showed the enzymatic activity of metallopeptidases on venoms of Brazilian Tityus scorpions (T. serrulatus, T. bahiensis and T. stigmurus), which is able to inactivate the neuropeptide dynorphin A (YGGFLRRIRPKLK), releasing Leu-enkephalin (YGGFL), another active human neuropeptide [23]. In another study, endopeptidases and exopeptidases from the T. serrulatus venom were able to cleave human peptides in vitro, with members of the neuropeptide $Y$ family being the best hydrolyzed substrates [24].

The observation that the venom of Tityus serrulatus contains metallopeptidases acting on essential human neuropeptides-dynorphin A (1-13), neuropeptide $Y$, peptide $Y Y$ and pancreatic polypeptide - was the motivation for the development of the present study, since the neurotoxic syndromes are the main symptoms presented by victims of accidents and these molecules are broadly distributed in the body, being found mainly in the adrenal gland, peripheral nervous system and also in immune cells [25-28]. Thus, here we describe the isolation and biochemical characterization of metalloserrulases 3 and 4, TsMS 3 and TsMS 4, from the T. serrulatus venom, and their in vitro proteolytic activities on human neuropeptides.

\section{Results}

\subsection{Isolation of TsMS 3 and TsMS 4}

Metalloserrulases 3 and 4 were purified following two chromatographic steps, as summarized in Table 1, which aimed to maintain the proteolytic activity upon dynorphin A (1-13)—Dyn A (1-13)—and its fluorescent homologue Abz-GFLRRV-EDDnp. First, the solubilized venom was fractioned by anion exchange chromatography and 4 active fractions were obtained (Figure 1, panel A). Fractions F3 and F5 stood out for having high hydrolysis rates on both substrates tested (Figure 1, panel B). However, a different hydrolysis pattern over dynorphin A 1-13 was observed. According to the mass spectrometry results, while fraction F3 hydrolyzed the substrate Dyn A (1-13) in the same manner as the total venom, releasing Leu-enkephalin (YGGFL) (Supplementary Figure S1, panel A), the fraction F5 activity presented only a single cleavage point, with no formation of Leu-enkephalin (only YGGFLR $\downarrow$ RIRPKLK) (Supplementary Figure S1, panel B). The SDS-PAGE showed that the F3 and F5 fractions have similar profiles, but with different intensities and some unique components in each fraction (Figure 1, panel C). Subfractions F3 and F5 also hydrolyzed neuropeptides from the neuropeptide $Y$ family (data not shown). Furthermore, all hydrolyzes over fluorescent and natural substrates were inhibited in the presence of the EDTA chelating agent, indicating metalloproteinases activities (Table 1).

Fractions F3 and F5 were then separately injected into a Diol-300 (Shim-pack) gel filtration column and the collected peaks were analyzed regarding hydrolysis upon dynorphin A (1-13) and FRET substrate. The resulting F3-4 subfraction from the second chromatographic step (Figure 2, panel A) was able to produce Leu-enkephalin from Dyn A (1-13) hydrolysis (Figure 2, panel C), and the electrophoretic profile demonstrates that fraction F3-4 had a single protein band with approximately $22 \mathrm{kDa}$ (Figure 2, panel B). The mass spectrometry analysis of the F3-4 identified 14 unique peptides from the metalloserrulase 3 sequence, covering around $19 \%$ of the zymogen molecule and $57 \%$ of its mature form (Figure 2, panel D).

Table 1. Summary of purification of metalloserrulases TsMS 3 and TsMS 4 from the Tityus serrulatus venom.

\begin{tabular}{|c|c|c|c|c|c|c|c|c|c|}
\hline Step & Fraction & $\begin{array}{l}\text { Volume } \\
(\mu \mathrm{L})\end{array}$ & $\begin{array}{c}\text { Total Protein } \\
(\mu \mathrm{g})\end{array}$ & $\begin{array}{l}\text { Activity } \\
\text { (units) }\end{array}$ & $\begin{array}{l}\text { Total Activity } \\
\text { (units } / \mu \mathrm{L} \text { ) }\end{array}$ & $\begin{array}{l}\text { Specific Activity } \\
\text { (units } / \mu \mathrm{g} \text { ) }\end{array}$ & $\begin{array}{l}\text { Purification } \\
\text { Factor }\end{array}$ & $\begin{array}{c}\text { Yield } \\
(\%)\end{array}$ & $\begin{array}{c}\text { EDTA } \\
\text { Inhibition } \\
(\%)\end{array}$ \\
\hline Venom & $\mathrm{TsV}$ & 1000 & 30,000 & 90 & 90,000 & 3000 & 1 & 100 & 100 \\
\hline \multirow{2}{*}{ DEAE } & F3 & 1000 & 0.12 & 13.1 & 13,100 & 109,167 & 36.39 & 14.6 & 100 \\
\hline & F5 & 1000 & 0.139 & 20.9 & 20,873 & 150,165 & 50.06 & 23.2 & 100 \\
\hline \multirow{2}{*}{ GF } & F3-4 & 1000 & 0.024 & 8.9 & 8900 & 370,833 & 123.61 & 9.9 & 100 \\
\hline & F5-1 & 1000 & 0.071 & 12.7 & 12,729 & 179,276 & 59.76 & 14.1 & 100 \\
\hline
\end{tabular}

The fluorescent substrate Abz-GFLRRV-EDDnp $(5 \mu \mathrm{M})$ and the EDTA $(100 \mathrm{mM})$ were used to screen the proteolytic activity. $\mathrm{DEAE}=$ anion exchange chromatography; $\mathrm{GF}=\mathrm{Gel}$ filtration chromatography. 
A)

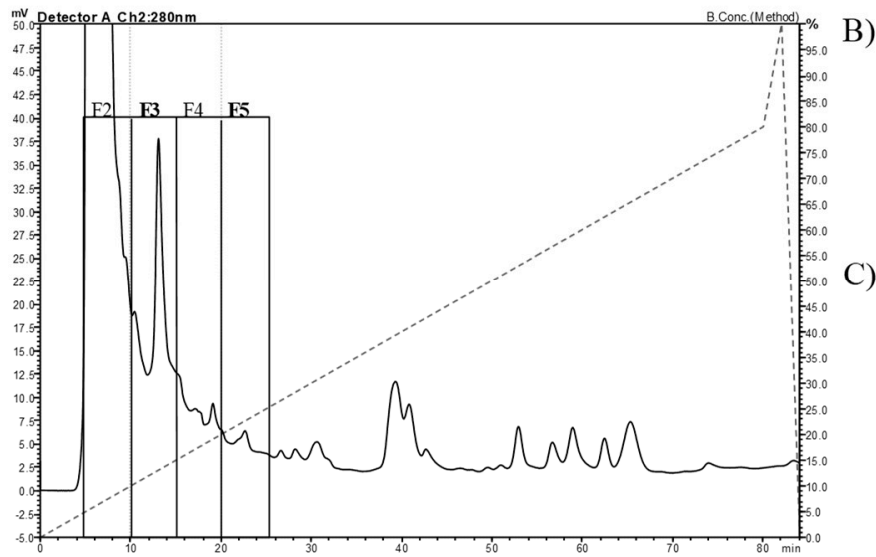

B)

\begin{tabular}{ccc}
\hline Fraction & $\begin{array}{c}\text { Dynorphin 1-13 } \\
(\boldsymbol{\mu M} / \mathbf{\mu g} / \mathbf{m i n})\end{array}$ & $\begin{array}{c}\text { Abz-GFLRRV-EDDnp } \\
\text { (UF/min) }\end{array}$ \\
\hline F2 & 0.26 & 14.0 \\
F3 & 1.00 & 72.0 \\
F4 & 1.43 & 64.0 \\
F5 & 0.44 & 78.0 \\
\hline
\end{tabular}

C)

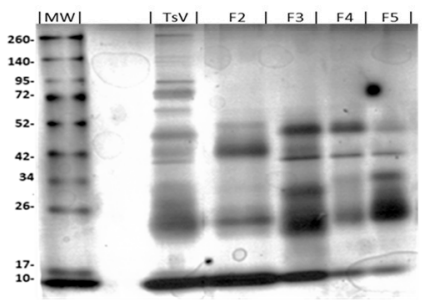

Figure 1. (A) Fractionation of Tityus serrulatus venom by anion-exchange chromatography on a PA-DEAE column in HPLC system. (B) Specific activity of fractions F2-F5 to substrates hydrolysis. The substrates used were dynorphin A 1-13, hydrolysis of which was visualized on the C-18 RP-HPLC system, and the fluorescent substrate Abz-GFLRRV-EDDnp, hydrolysis of which was monitored using fluorimeter Victor 3 (Perkin Elmer). (C) The SDS-PAGE (12\%) of active fractions eluted from the PA-DEAE. Lane MW: molecular mass markers; lane TsV: T. serrulatus venom.

A)

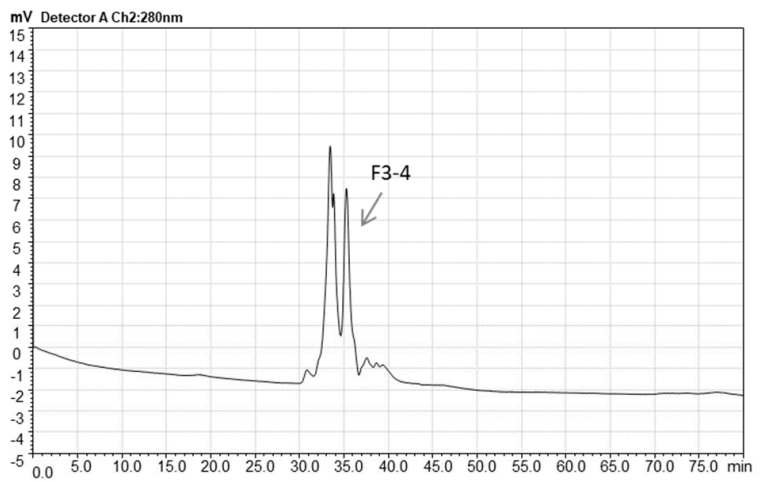

B)

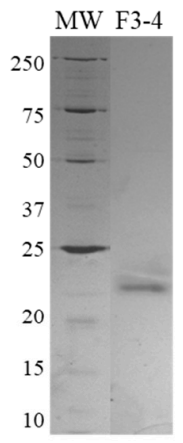

C)

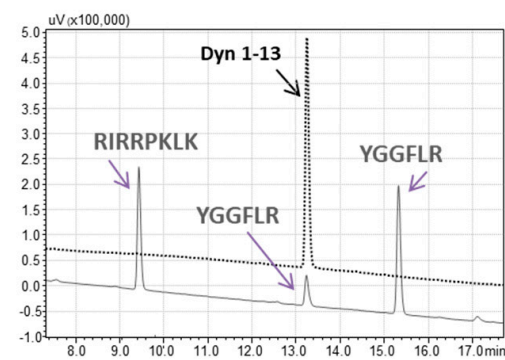

D)
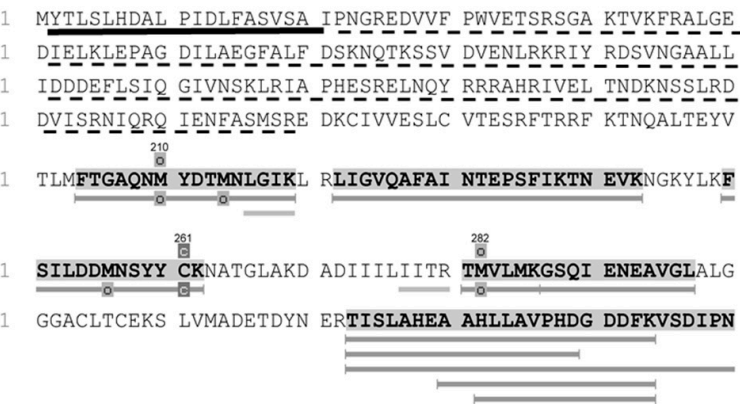

351 SPGAKSCRYG EGYIMGTSIG PNMLKFSKCS IACAKYFLSL PQASCLYEDC

401 PSSAY $\quad$ Carbamidomethyation $(+57.02$

Figure 2. (A) Rechromatography on Shim-pack Diol-300 of fraction 3 from anion exchange chromatography. The arrow indicates the peak containing proteolytic activity on the FRET and Dyn A (1-13) substrates, with Leu-enkephalin releasing. (B) SDS-PAGE (12\%) analysis of F3-4 (2 $\mu \mathrm{g})$ under non-reduced conditions. (C) Proteolytic activity over Dyn A (1-13) by F3-4, hydrolysis of which was visualized on the C-18 RP-HPLC system (Shimadzu). (D) The mass spectrometry analysis identified F3-4 as metalloserrulase 3. The sequence underlined in black represent the signal peptide and the dotted lines represent the propeptide. Highlighted and underlined amino acids in grey represent the peptides sequenced by PEAKS Studio 8.0. The amino acids that are just underlined in grey are the ones that are found in de novo sequencing only. 
Regarding the subfractions resulting from the F5 gel filtration chromatographic step, F5-1 (Figure 3, panel A) was the only one which was able to cleave the substrate Abz-GFLRRV-EDDnp. Dynorphin A (1-13) was also cleaved by F5-1, with no Leu-enkephalin formation (Figure 3, panel C). Finally, the silver stained $12 \%$ polyacrylamide gel demonstrated a single protein band with $24 \mathrm{kDa}$ (Figure 3, panel B). The mass spectrometry analysis of F5-1 identified the molecule as metalloserrulase 4 , where 9 peptides covered around $17 \%$ of the total molecule and $32 \%$ of its mature form (Figure 3, panel D).

A)

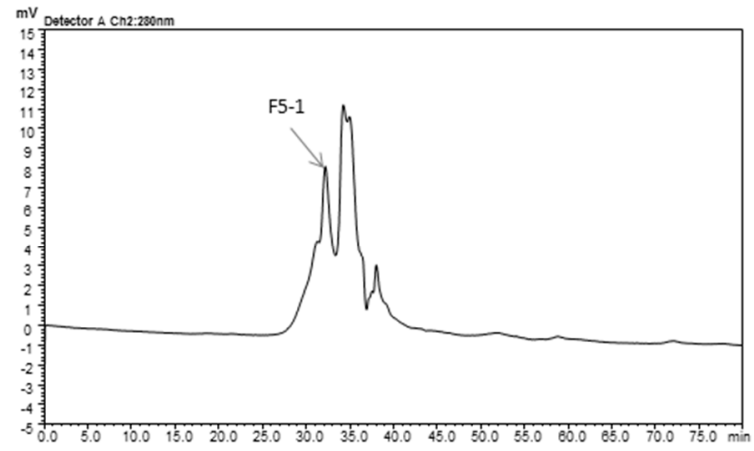

B)

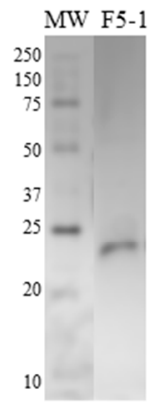

C)

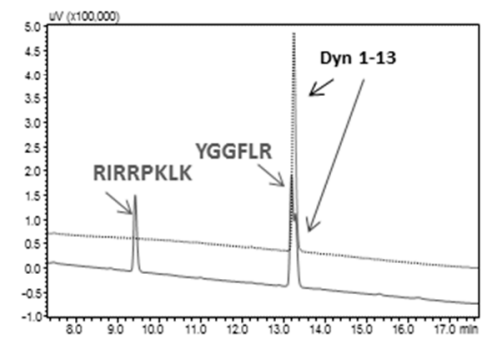

D)

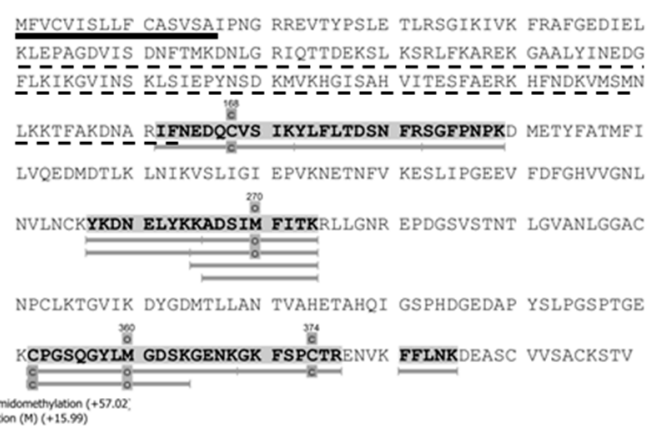

Figure 3. (A) Rechromatography on Shim-pack Diol-300 of fraction 5 from anion exchange chromatography. The arrow indicates the peak containing the active protease. (B) SDS-PAGE (12\%) analysis of F5-1 (2 $\mu \mathrm{g})$ under non-reduced conditions. (C) Proteolytic activity over Dyn A (1-13) by F5-1, hydrolysis of which was visualized on the C-18 RP-HPLC system (Shimadzu). (D) The mass spectrometry analysis identified F5-1 as metalloserrulase 4 . The sequence underlined in black represents the signal peptide and the dotted line represents the propeptide region. Highlighted and underlined amino acids in grey represent the peptides sequenced by PEAKS Studio 8.0.

\subsection{Bioinformatic Analysis}

Due to the different cleavage sites in Dyn A (1-13), the extended zinc-binding of metalloserrulases 3 and 4 were aligned using the BLAST tool (Figure 4 ). The alignment demonstrated $44.7 \%$ identity and $60.5 \%$ similarity between these two catalytic domains. Moreover, metalloserrulase 4 has the conserved

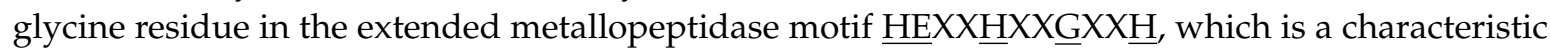
of the family called "metzincins", while metalloserrulase 3 has an alanine instead of glycine in this motif. Furthermore, the probable position of Met-turn methionine for both metalloserrulases is shown in Figure 4, which was previously estimated by [16]. 
A)

B)
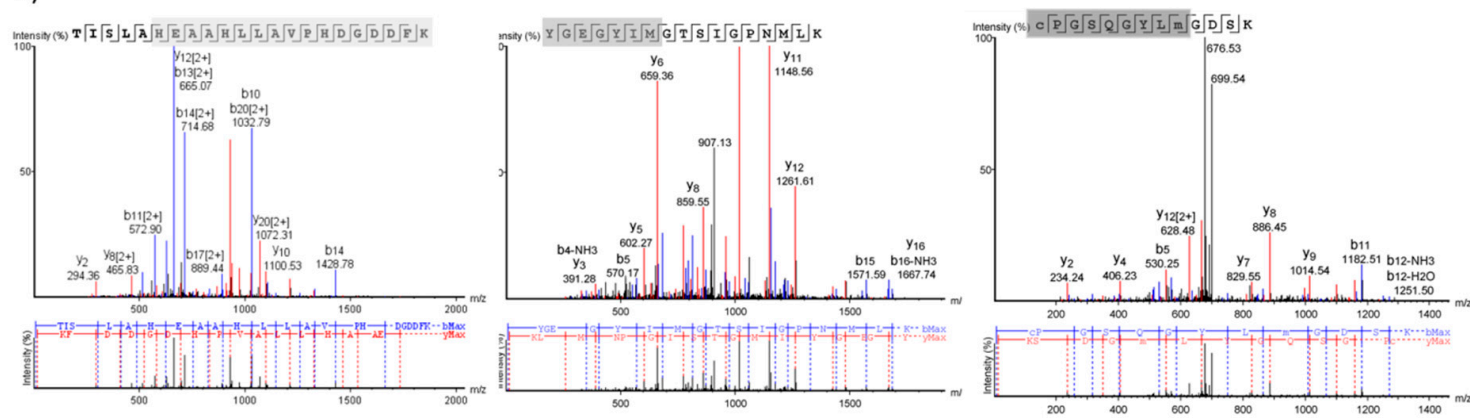

Figure 4. (A) Alignment of the extended zinc-binding sites of metalloserrulases 3 (TsMS 3) and 4 (TsMS 4). The sequence of the active site of metzincins, HEXXHXXG (A)/XXH is shown in the dashed box. The probable methionine residues (M) from the Met-turn region are in bold. (B) MS/MS spectra containing the peptides in the region of the extended active site. The highlighted sequenced fragments are also colored in Panel A.

\subsection{Comparative Analysis of Metalloserrulases Biochemical Parameters}

Since TsMS 3 and TsMS 4 were purified for the first time, we aimed to perform an initial biochemical characterization of these enzymes in vitro. The catalytic activities of both metalloserrulases were evaluated in a $\mathrm{pH}$ range from 5.0 to 10.0 (Figure 5, panel A). For both proteases, a better proteolytic activity on alkaline rather than acid buffers was observed. The best activity was achieved at $\mathrm{pH} 8.0$ for metalloserrulase 3, and at $\mathrm{pH} 8.5$ for metalloserrulase 4. When Abz-GFLRRV-EDDnp was used as substrate, the specific activity of TsMS 4 is twice the activity of TsMS 3 in all studied pHs. Corroborating with this, the greater specific activity of TsMS 4 on the FRET substrate is also shown in results obtained in studies of cations influence and temperature effects (Figure 5, panel B and C, respectively).

A

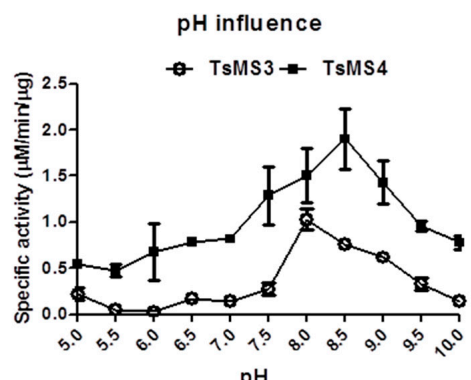

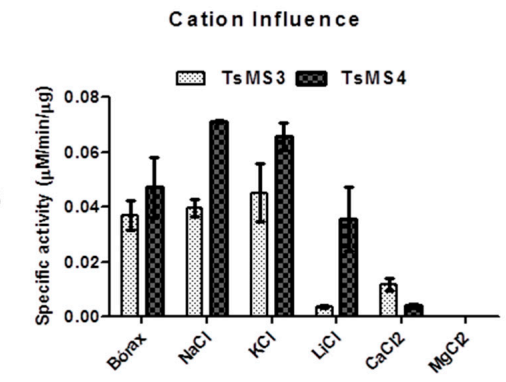

Temperature Influence

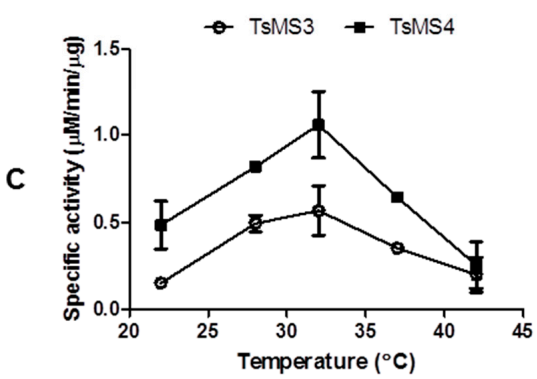

Figure 5. Initial biochemical characterization of the two metalloserrulases using the Abz-GFLRRV-EDDnp $(5 \mu \mathrm{M})$ as substrate. (A) Evaluation of optimum $\mathrm{pH}$ from $\mathrm{pH} 5$ to $\mathrm{pH}$ 10; (B) Influence of monovalent and divalent cations; (C) Thermo-stability study between $22{ }^{\circ} \mathrm{C}$ and $42{ }^{\circ} \mathrm{C}$. All assays were made in triplicate. 
The evaluation of the influence of monovalent $\left(\mathrm{Li}^{+}, \mathrm{Na}^{+}, \mathrm{K}^{+}\right)$and divalent cations $\left(\mathrm{Mg}^{2+}, \mathrm{Ca}^{2+}\right)$ on the enzymatic activity of TsMS 3 and TsMS 4 was determined in fluorimeter with the addition of cations as chloride $(50 \mathrm{mM})$ using borax buffer $50 \mathrm{mM}, \mathrm{pH} 8.5$ at $37^{\circ} \mathrm{C}$, which was used as control (Figure 5, panel B). In general, metalloserrulases are positively affected by $\mathrm{Na}^{+}$and $\mathrm{K}^{+}$, but not $\mathrm{Li}^{+}$. The negative influence of lithium was more drastic for TsMS 3 activity than for TsMS 4 . On the other hand, the presence of divalent cations caused a decrease of TsMS 3 and TsMS 4 activities, but it was less expressive for metalloserrulase TsMS 3 in comparison to TsMS 4. Magnesium at the concentration used $(50 \mathrm{mM})$ was able to completely inhibit the activity of both metalloserrulases.

The thermo-stability was also tested and, in general, metalloserrulases 3 and 4 behaved in the same way over temperature variations (Figure 5, panel C). Both had an optimum peak of activity at $32{ }^{\circ} \mathrm{C}$, and were active at all temperatures in the tested range. At $42{ }^{\circ} \mathrm{C}$, however, proteolytic activity of TsMS 3 and TsMS 4 decreased around 50\%, indicating a possible denaturation of proteins.

\subsection{Determination of Cleavage Sites}

The cleavage point produced by metalloserrulase 3 and metalloserrulase 4 over the fluorescent substrate analogous to dynorphin A (1-13), Abz-GFLRRV-EDDnp, was determined, as described [29]. As expected, metalloserrulase 4 formed only a single cleavage point between Arg-Arg; for TsMS 3 , two cleavage sites were obtained: between Arg-Arg and between Leu-Arg.

The scissile bonds and specific activities were also determined, as described [21], for the NPY, PYY, PP and dynorphin A (1-13) hydrolyses produced by metalloserrulases 3 and 4 (Table 2), which allowed for the analysis of the primary specificity of these proteases (Figure 6).

Table 2. Specific activities and cleavage points produced by metalloserrulases $3(\uparrow)$ and $4(\downarrow)$ in the neuropeptide Y (NPY), peptide YY (PYY), polypeptide pancreatic (PP) and Dyn A (1-13) (DYN). The cleavage sites shared by both peptidases are highlighted in light grey.

\begin{tabular}{|c|c|c|c|}
\hline \multirow[t]{2}{*}{ Peptide } & \multicolumn{2}{|c|}{$\begin{array}{l}\text { Specific Activity } \\
(\mu \mathrm{M} / \mu \mathrm{g} / \mathrm{min})\end{array}$} & \multirow[t]{2}{*}{ Scissile Bonds } \\
\hline & TsMS 3 & TsMS 4 & \\
\hline NPY & 0.433 & 0.631 & 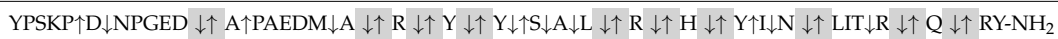 \\
\hline PYY & 0.359 & 0.420 & YPIKPEAPGED $\downarrow$ ASPEEL $\downarrow N \downarrow R \downarrow$ YYASL $\downarrow \uparrow R \downarrow H Y \downarrow L \downarrow N L V T \uparrow R \downarrow Q \downarrow \downarrow R Y-N_{2}$ \\
\hline $\mathrm{PP}$ & 0.347 & 0.430 & APLEPMYP $\downarrow \mathrm{G} \uparrow \mathrm{D} \uparrow \mathrm{Y} \uparrow \mathrm{A} \uparrow \mathrm{TH} \uparrow \mathrm{E} \uparrow \mathrm{Q} \uparrow \mathrm{RAQ} \uparrow \mathrm{YETQL} \downarrow \uparrow \mathrm{R} \uparrow \mathrm{R} \downarrow \uparrow \mathrm{Y} \uparrow \mathrm{YPIKPE} \downarrow \uparrow \mathrm{PRY}-\mathrm{NH}_{2}$ \\
\hline DYN & 1.539 & 1.303 & YGGFL $\uparrow R \downarrow \uparrow$ RIRPKLK \\
\hline
\end{tabular}

The peptides were incubated with proteases and the specific activity was determined on RP-HPLC. The peaks corresponding to the hydrolysis products were analyzed on mass spectrometry to determine the cleavage sites (see experimental details in Section 5.4.3).

Both metalloserrulases cleaved the amidated C-terminal portion of the three peptides belonging to the neuropeptide $\mathrm{Y}$ family (Table 2). These cleavages lead to the inactivation of these neuropeptides, since the C-terminal part is responsible for binding with their receptors [30]. Table 2 shows that neuropeptide $\mathrm{Y}$ was the most susceptible substrate for the metalloserrulases tested, presenting a greater number of cleavage points (17 cleavage points for TsMS 4, and 14 for TsMS 3) when compared with the other substrates, which presented 10 hydrolysis sites or less. Some hydrolysis points are shared by both metalloserrulases (Table 2, grey enhancement), however, most fragments are unique to each peptidase, indicating different primary specificities for these enzymes. In terms of specific activity, both metalloproteases show high hydrolysis rates of Dyn A (1-13), followed by neuropeptide Y. In comparison, Dyn A (1-13) is most efficiently cleaved by TsMS $3(1.54 \mu \mathrm{M} / \mu \mathrm{g} / \mathrm{min})$ than TsMS 4 $(1.3 \mu \mathrm{M} / \mu \mathrm{g} / \mathrm{min})$. On the other hand, TsMS 4 have a higher contribution on the degradation of the neuropeptide $Y$ than TsMS $3(0.631 \mu \mathrm{M} / \mu \mathrm{g} / \mathrm{min}$ and $0.433 \mu \mathrm{M} / \mu \mathrm{g} / \mathrm{min}$, respectively). According to the data obtained by the IceLogo software, the preference for arginine in the P1 position was significant for metalloserrulase 4, and in the $\mathrm{P} 1^{\prime}$ position for TsMS 3. Moreover, metalloserrulase 3 may interact with a glutamine $(\mathrm{Q})$ in the $\mathrm{P} 1$ position in addition to recognizing Arg and Tyr (Figure 6). 
A TsMS 3

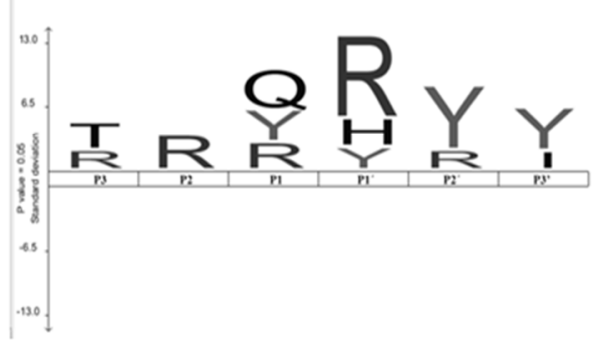

B TsMS 4

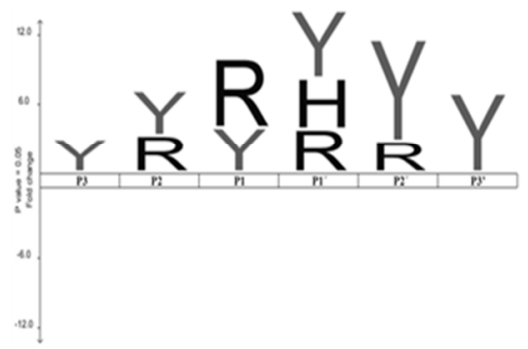

Figure 6. Preliminary study of primary specificities of metalloserrulase 3 and metalloserrulase 4 based on cleavage points on peptides belong to the neuropeptide $Y$ family and dynorphin A (1-13), using the IceLogo software [31]. (A) IceLogo of amino acid position preference on substrates by metalloserrulase 3; and (B) by metalloserrulase 4 .

\subsection{Kinetic Parameters Determination}

The obtainment of the Michaelis-Menten $\left(\mathrm{K}_{m}\right)$ and catalytic $\left(\mathrm{k}_{\text {cat }}\right)$ constants for hydrolysis of Dyn A (1-13) analogous FRET substrates (Abz-GFLRRV-EDDnp, Abz-GFLRR-EDDnp, and Abz-FLRRV-EDDnp) by metalloserrulases 4 was performed with increasing substrate concentrations. All kinetics were fitted to the hyperbolic Michaelis-Menten rate equation and the results are shown in Table 3. TsMS 4 hydrolyzed all substrates at Arg-Arg bond. On the other hand, metalloserrulase 3 recognized the sequences in two peptide bonds (Leu-Arg and Arg-Arg) and, thus, it was not possible to determine the catalytic constants for the hydrolysis of these substrates (Supplementary Figure S2).

Among all substrates analyzed, the Abz-GFLRRV-EDDnp presented the lowest value of $\mathrm{K}_{m}$ $(16.2 \mu \mathrm{M})$, indicating that the largest sequence had the best interaction with TsMS 4 . The C-terminal valine, which interacts with the $S^{\prime} 2$ subsite, was shown to be an important factor for TsMS 4 activity, since its catalytic efficiency on the Abz-GFLRR-EDDnp substrate was drastically reduced, both for presenting the lowest $\mathrm{k}_{c a t}$ value $\left(170 \mathrm{~s}^{-1}\right)$ and the highest $\mathrm{K}_{m}$ value $(36.6 \mu \mathrm{M})$ of all studied sequences. In the same way, the presence of glycine in $\mathrm{P} 4$ seems to help the substrate to bind in the protease catalytic pocket, as the $\mathrm{K}_{m}$ value for the Abz-FLRRV-EDDnp $(28.1 \mu \mathrm{M})$ is higher than the $\mathrm{K}_{m}$ obtained for Abz-GFLRRV-EDDnp hydrolysis $(16.2 \mu \mathrm{M})$. However, the presence of a glycine at the P4 position negatively affected the $\mathrm{k}_{c a t}$ value, which is about twice as low for the Abz-GFLRRV-EDDnp $\left(492 \mathrm{~s}^{-1}\right)$ when compared to the Abz-FLRRV-EDDnp substrate $\left(1108 \mathrm{~s}^{-1}\right)$. Based on the specificity constants $\left(\mathrm{k}_{\text {cat }} / \mathrm{K}_{m}\right)$, the best substrate tested was the Abz-FLRRV-EDDnp $\left(39.4 \mu \mathrm{M}^{-1} \mathrm{~s}^{-1}\right)$.

Table 3. Determination of catalytic constants for FRETs substrate hydrolysis by metalloserrulase 4 .

\begin{tabular}{|c|c|c|c|c|c|c|c|c|c|c|}
\hline & \multicolumn{7}{|c|}{ Substrate } & \multicolumn{3}{|c|}{ Catalytic Constants } \\
\hline & P4 & P3 & P2 & P1 & $\mathbf{P} \mathbf{1}^{\prime}$ & $\mathbf{P} \mathbf{2}^{\prime}$ & & $\mathbf{K}_{m}(\mu \mathbf{M})$ & $\mathbf{k}_{\text {cat }}\left(\mathrm{s}^{-1}\right)$ & $\mathbf{k}_{c a t} / \mathbf{K}_{m}\left(\mu \mathbf{M}^{-1} \cdot \mathrm{s}^{-1}\right)$ \\
\hline $\mathrm{Abz}$ & G & F & $\mathrm{L}$ & $\mathrm{R}$ & $\mathrm{R}$ & V & EDDnp & $16.2 \pm 4.3$ & $491.7 \pm 52.4$ & $30.4 \pm 8.1$ \\
\hline $\mathrm{Abz}$ & G & $\mathrm{F}$ & $\mathrm{L}$ & $\mathrm{R}$ & $\mathrm{R}$ & - & EDDnp & $36.6 \pm 5.8$ & $170.8 \pm 8.4$ & $4.7 \pm 0.7$ \\
\hline $\mathrm{Abz}$ & - & $\mathrm{F}$ & $\mathrm{L}$ & $\mathrm{R}$ & $\mathrm{R}$ & $\mathrm{V}$ & EDDnp & $28.1 \pm 2.6$ & $1108.3 \pm 33.2$ & $39.4 \pm 3.64$ \\
\hline
\end{tabular}

\subsection{In Vitro Neutralization Assay of the Activity of Metalloserrulases by Commercial Antivenoms}

As shown in Figure 7, the in vitro neutralization assay demonstrated effectiveness even in low amounts of antivenom (venom/antivenom mass ratio of 1:20). For TsMS 3, the neutralization by the arachnidic antivenom (AAV) showed earlier inhibition than scorpion antivenom (SAV). In contrast, TsMS 4 was, in general, equally neutralized by both antivenoms. For both proteases, an increase in inhibition was observed with higher amounts of antivenoms, and the full neutralization was reached at 1:500 in all cases, except SAV for TsMS 4 (which was 1:200). 
A)

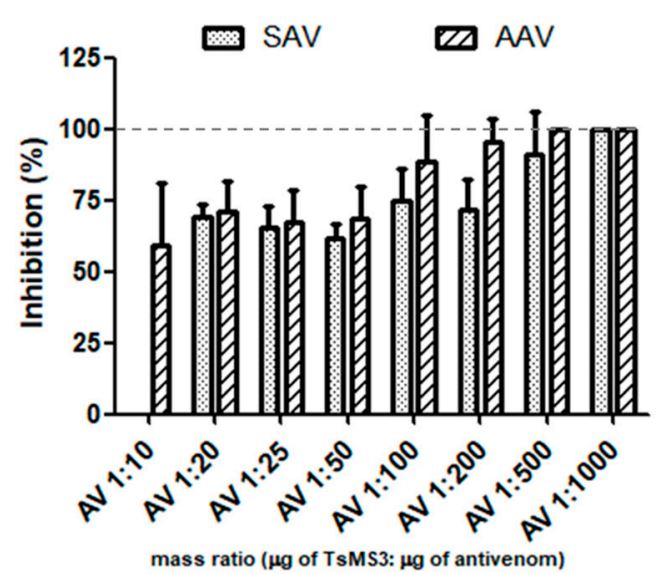

B)

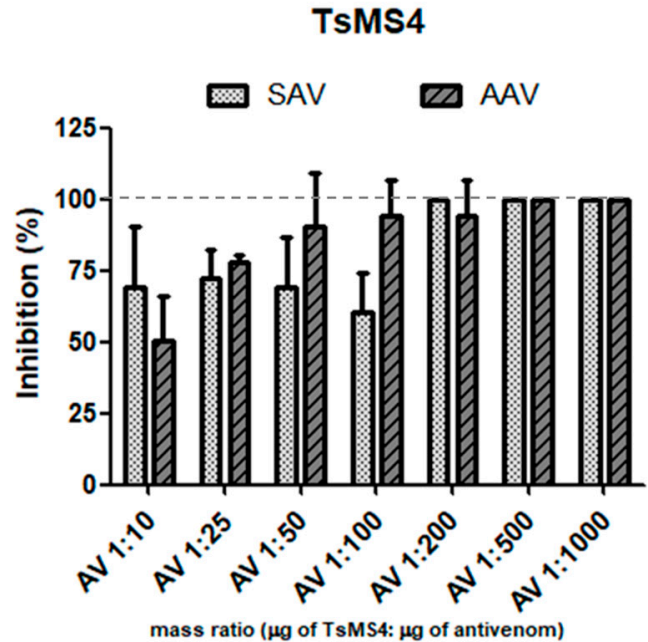

Figure 7. Neutralization assay of isolated proteases using the substrate Abz-FLRRV-EDDnp (A) Inhibition of TsMS 3 (88 ng) and (B) TsMS 4 activities (100 ng) in PBS buffer pH 7.4. Proteases and antivenoms were previously incubated without the substrate, for $30 \mathrm{~min}$ at $37^{\circ} \mathrm{C}$, in seven different proportions (protease mass/antivenom mass ratio): 1:10; 1:25; 1:50; 1:100; 1:200; 1:500 and 1:1000, and their hydrolysis rates were compared to the control (without antivenom). The results are the average of three independent experiments and expressed as percentage of the inhibition of each metalloserrulase activity. SAV = scorpion antivenom and AAV = arachnidic antivenom.

\section{Discussion}

The study of isolated toxins in animal venoms is an important step to identify functions of new molecules or even to better understand envenomation mechanisms. For proteases of the Tityus serrulatus venom, it may be understood that its action is associated only with post-translational events, since $80 \%$ of peptides identified in the venom are proteolytic products of endogenous toxins [22], or, in addition, that they may also be enzymes that could play important roles in the envenoming. To date, metalloserrulases have only been detected in the cDNA library of the Tityus serrulatus scorpion venom gland, selected according to homology with the proteases belonging to the M13 class of metalloproteases [16]. Although this approach represents important evidence of their presence in the venom, it is necessary to confirm whether metalloserrulases 3 and 4 are actually toxins of the T. serrulatus venom. This is the first report on the isolation and characterization of the proteolytic activities of these two active metalloserrulases that are present in the T. serrulatus venom, metalloserrulases 3 and 4 , which surely will help on further studies with these enzymes.

Metalloserrulases 3 and 4 were purified to homogeneity by two chromatographic steps and their identities were confirmed by mass spectrometry analysis. The molecular masses predicted for the active forms of TsMS 3 and TsMS 4 are $22 \mathrm{kDa}$ and $26 \mathrm{kDa}$ [16], respectively. The molecular mass of the TsMS 3 is in agreement with the electrophoretic profile obtained with this metalloserrulase, which presents a protein band of approximately $22 \mathrm{kDa}$. On the other hand, the metalloserrulase 4 presented migration rate compatible with a protein with molecular mass of $24 \mathrm{kDa}$. Two facts may explain this divergence from $26 \mathrm{kDa}$ to $24 \mathrm{kDa}$ - the mature portion of the metalloserrulase 4 molecule has been estimated in in silico studies and may contain deviations, or the purified molecule underwent post-translational modifications and still exhibits catalytic activity. The primary structure of the metalloserrulase 4 shows a metzincins zinc-binding consensus sequence, HETAHQIGSPH, which includes three protein ligands of the catalytic zinc and the general base/acid glutamate for catalysis. Interestingly, the metalloserrulase 3 has an alanine residue instead of glycine, HEAAHLLAVPH, and it is important to note that this unusual feature of the TsMS 3 was confirmed in the mass spectrometric analyzes presented in this study. Another characteristic common to metzincins is the presence of a Met-turn that is structurally and spatially conserved, and distanced by 6-53 amino acids from the third zinc-binding 
histidine in the different metzincin structures [32]. In accordance with previous results obtained with antarease [17], alignment studies of extended binding sites of TsMS 3 and TsMS 4 indicate the presence of conserved methionine residues, which are separated from the first histidine by connecting segments of 38 and 37, amino acids residues, respectively. Peptide fragments containing the Met residues were also sequenced on the two metalloserrulases in mass spectrometric analyzes performed.

The first biochemical analyses with TsMS 3 and TsMS 4 aimed to determine the optimum levels of three physical-chemical parameters ( $\mathrm{pH}$, temperature and cations effects), so that the obtained results could be used in the subsequent studies of their hydrolytic activities on neuropeptides. As previously determined for the venom of T. serrulatus [23], a pH of 8.5 was defined as optimal for metalloserrulase 4 . The ideal $\mathrm{pH}$ for the metalloserrulase 3 activity was determined as 8.0, followed by 8.5 , where the protease also showed a high level of proteolytic activity. Regarding thermo-stability studies of the molecules, in general both metalloserrulases behaved in the same way with temperature variations - probably due to the ectothermic nature of scorpions-and both metalloserrulases had an optimum activity peak at $32{ }^{\circ} \mathrm{C}$. However, at $42{ }^{\circ} \mathrm{C}$ the proteolytic activity decreased by about $50 \%$ for both metalloserrulases, indicating a possible denaturation of the enzymes' secondary and tertiary structures. Lastly, it is known that the presence of cations commonly interferes with the proteolytic activity, either enhancing or inactivating enzymes. It was possible to observe a positive influence of monovalent cations, especially sodium and potassium, and negative influence by divalent ions, such as magnesium and calcium. Both metalloserrulases were inhibited by divalent cations, which can act as competitors of the zinc at the catalytic site, causing its substitution and, thus, destabilizing the enzyme [33].

Although the use of a greater number of substrates for a more accurate primary specificity study would be best, the preliminary results presented here, using the cleavage points obtained on peptides belonging to the neuropeptide $Y$ family and dynorphin A (1-13), provided relevant information on preferences of the metalloserrulases 3 and 4 for the hydrolysis of substrates. For both, a high preference was observed for the interaction of arginine and tyrosine residues with the S3-S3' subsites, regardless of their positions. However, arginine residues are most frequently found in the $\mathrm{P} 1$ and $\mathrm{P} 1^{\prime}$ positions on substrates hydrolyzed by TsMS 4 and TsMS 3, respectively. This fact may explain the exclusive Leu-enkephalin releasing (YGGFL) from the hydrolysis of dynorphin $A$ $\left(\mathrm{Y}^{1} \mathrm{G}^{2} \mathrm{G}^{3} \mathrm{~F}^{4} \mathrm{~L}^{5} \mathrm{R}^{6} \mathrm{R}^{7} \mathrm{I}^{8} \mathrm{R}^{9} \mathrm{P}^{10} \mathrm{~K}^{11} \mathrm{~L}^{12} \mathrm{~K}^{13}\right)$ by TsMS 3, since the two cleavage sites, $\mathrm{Leu}^{5}-\mathrm{Arg}^{6}$ and $\mathrm{Arg}^{6}-\mathrm{Arg}^{7}$, were observed to have arginine residues in the $\mathrm{P}^{\prime}$ position of the substrate. It is important to consider that the cleavage site between arginine residues is characteristic of processing proteases for the activation of precursor molecules [34], which could reinforce the suggestion of the actions of the metalloserrulases as post-translational agents in endogenous venom toxins, as previously described for a protease purified from the Cupiennius salei spider venom [22,35].

The metalloserrulases showed the same primary specificity for the Abz- $G^{1} F^{2} L^{3} R^{4} R^{5} V^{6}$-EDDnp hydrolysis already evidenced in the studies with dynorphin A (1-13), that is, TsMS 3 cleaved the substrate at two points $\left(\mathrm{Leu}^{3}-\mathrm{Arg}^{4}\right.$ and $\mathrm{Arg}^{4}-\mathrm{Arg}^{5}$ ), whereas TsMS 4 was capable of hydrolyzing a single peptide bond $\left(\mathrm{Arg}^{4}-\mathrm{Arg}^{5}\right)$. Considering that the FRET substrate is cleaved by TsMS 4 with a single-cleavage point, it was possible to perform a deeper substrate-specificity study. The best FRET substrate tested was Abz-FLRRV-EDDnp, and both the removal of valine from the C-terminus and the addition of a glycine residue in the N-terminus decreased TsMS 4 catalytic efficiency. The primary specificity results, although preliminary, are robust evidence of an extended binding site for both metalloserrulases to interact with substrates.

Metalloserrulases 3 and 4 were able to remove in vitro the carboxy amidation of NPY, PP and YY, which leads to the inactivation of the biological activities of these peptides [30]. The three peptides belonging to the neuropeptide $Y$ family are widely distributed in the body and act through several subtypes of G-protein-coupled Y receptors [28]. Neuropeptide $Y$ is the most abundant neuropeptide in the central and peripheral nervous systems in mammals and has been implicated in different activities ranging from the control of anxiety to angiogenesis and cardiovascular function [26,36]. PYY and PP 
are mainly contained in the pancreas and gastrointestinal mucosa and, in particular, the pancreatic polypeptide is related to diseases of the pancreas, such as pancreatitis [37]. The inactivation of Dyn A (1-13) and the release of Leu-enkephalin during the envenomation process may lead to unexpected consequences, as this neuropeptide may act in vivo on both opioid and non-opioid receptors, and can interact with potassium ion channels promoting indirect neurotoxicity [38,39]. Dynorphin A (1-13) is also released by immune cells locally during painful inflammation $[25,40]$, which is a condition observed in in vivo studies with Tityus serrulatus venom [41]. In spite of the fact that there can be significant differences between in vivo and in vitro results, it is possible that these neuropeptides are targets for the metalloserrulases during the envenomation process. This hypothesis should be checked by further in vivo studies with isolated proteases.

Since the WHO's recommendation in case of human accidents with venomous scorpions is immunotherapy, serum neutralization assays using commercial antivenoms were performed. Neutralization assays results demonstrated effective inhibitions of activities of both metallopeptidases when using the two commercial antivenoms produced by the Butantan Institute. Surprisingly, the activity of TsMS 3 was more efficiently inhibited by the lowest dose used of anti-arachnidic serum when compared to the same dose of anti-scorpion serum. To explain this result, we hypothesized that the other two spider venoms used to compose the immunization pool to obtain the AAV (Phoneutria nigriventer-21.5\% — and Loxosceles gaucho-21.5\%) may contain metalloproteases that share epitopes with the TsMS 3. Regarding the venom of Loxosceles intermedia, an astacin-like metalloprotease has been described, which presents a $21 \%$ similarity with metalloserrulase 3 [42]. Despite the satisfactory results obtained in the serum neutralization assays, and since the action of peptidases is usually rapid, it is important to consider that the immediate onset of immunotherapy after the accident is crucial for the treatment of the victims. Otherwise, cleavages of bioactive peptides, if they occur during envenomation, are initiated and trigger their physiological effects.

Recently our group demonstrated that the T. serrulatus venom proteases are indicative of the venom's toxicity, since venom batches with lower proteolytic activities over the FRET substrate showed higher $\mathrm{LD}_{50}$ values, and therefore are less toxic in comparison to the batches with greater hydrolytic activities [43]. In this manner, metalloserrulases 3 and 4 may be important toxins from the venom, acting in the formation or inactivation of human neuropeptides, besides being responsible for the maturation of endogenous peptides [22].

\section{Conclusions}

In conclusion, this study describes the purification and characterization of two novel metallopeptidases from the T. serrulatus venom, acting upon human neuropeptides in in vitro studies. Since the TsV has neurotoxic effects, mainly attributed to molecules without enzymatic activity, it is possible that human neuropeptides degradation may also have an important role in the envenomation process.

\section{Materials and Methods}

\subsection{Reagents}

Dynorphin A (1-13), neuropeptide $Y$, peptide $Y Y$ and pancreatic polypeptide were purchased from Sigma-Aldrich (St Louis, MO, USA). Acetonitrile and trifluoroacetic acid (TFA) were acquired from J.T. Baker. The fluorescent resonance energy transfer (FRET) substrates Abz-GFLRRV-EDDnp, Abz-FLRRV-EDDnp and Abz-GFLRR-EDDnp were kindly provided by Prof. Dr. Luiz Juliano Neto and Prof. Dr. Adriana Carmona, from the Department of Biophysics of UNIFESP-EPM.

\subsection{Venoms and Antivenoms}

The lyophilized venom of Tityus serrulatus (Batch no. 2146) was provided by the Venom Section of the Butantan Institute, SP, Brazil. The scorpion and the arachnidic antivenoms (SAV and AAV, 
respectively) were obtained from Hyperimmune Plasmas Processing Section, Butantan Institute, SP, Brazil. The SAV (batch no 0905104/A) and the AAV (batch no 0706121) contained protein concentrations of $8.43 \mathrm{~g} / \mathrm{dL}$ and $15.4 \mathrm{~g} / \mathrm{dL}$, respectively. The antivenoms from the Butantan Institute are produced through the hyperimmunization of horses with a pool of T. serrulatus venom $(100 \%)$ for SAV, and T. serrulatus (57\%), Phoneutria nigriventer (21.5\%) and Loxosceles gaucho (21.5\%) venoms for AAV [44].

\subsection{Purification of Metalloserrulases 3 and 4 from Tityus serrulatus Venom}

\subsubsection{Chromatographic Steps}

The lyophilized Tityus serrulatus venom ( $50 \mathrm{mg}$ ) was dissolved on $5 \mathrm{~mL}$ of $20 \mathrm{mM}$ Tris, $20 \mathrm{mM} \mathrm{NaCl}$, $\mathrm{pH} 8.2$ buffer (final concentration $10 \mathrm{mg} / \mathrm{mL}$ ). The TsV was first submitted to anion exchange chromatography in an HPLC system (Prominence, Shimadzu Co, Kyoto, Japan) using a Shim-Pack PA-DEAE column $(20 \mathrm{~mm} \times 100 \mathrm{~mm})$ at $4 \mathrm{~mL} / \mathrm{min}$ flow. The gradient used was $0-80 \% \mathrm{~B}$ in $80 \mathrm{~min}$ (buffer A containing $20 \mathrm{mM}$ Tris, $20 \mathrm{mM} \mathrm{NaCl}$, pH 8.2 and buffer B composed by buffer A with addition of $\mathrm{NaCl} 500 \mathrm{mM}, \mathrm{pH}$ 8.2). For salt removal, the fractions were submitted to a Millipore Amicon Ultra Centrifugal filter device (10 kDa MWCO, Amicon Co. Ltd., Bedford, MA, USA), following the manufacturer instructions. After the selection of active fractions (as described in Sections 5.3.2 and 5.3.3), they were applied to a Shim-pack Diol-300 $(7.9 \mathrm{~mm} \times 50 \mathrm{~cm})$ gel filtration column coupled to an HPLC system (Prominence, Shimadzu Co, Kyoto, Japan) and was eluted with $200 \mathrm{mM}$ sodium sulfate, $10 \mathrm{mM}$ sodium phosphate, $\mathrm{pH} 7.0$ buffer at $0.5 \mathrm{~mL} / \mathrm{min}$ flow rate in $80 \mathrm{~min}$. Lastly, active subfractions were concentrated with a Millipore Amicon Ultra centrifugal filter device (10 kDa MWCO, Amicon Co. Ltd., Bedford, MA, USA), also using the manufacturer recommendations. For all chromatographic steps, UV detection was at $280 \mathrm{~nm}$.

\subsubsection{Screening Using FRET Substrate}

For endopeptidase activity screening, the Abz-GFLRRV-EDDnp substrate $(5 \mu \mathrm{M})$ was incubated individually with each fraction collected from all chromatographic steps. Moreover, the relative inhibition of active fractions was determined using EDTA at $100 \mathrm{mM}$. The results using FRETs substrates were obtained on a fluorimeter (Victor 3, Perkin Elmer, MA, USA), adjusted for excitation and emission readings at 320 and $420 \mathrm{~nm}$, respectively, and analyzed using the Grafit 5 software (Erithacus Software, West Sussex, UK). The temperature remained constant at $37^{\circ} \mathrm{C}$ and one reading per minute was performed for $15 \mathrm{~min}$, the plates being shaken before each measurement.

\subsubsection{Screening Using Human Neuropeptides}

In parallel to the fluorimetric screening, the cleavage of Dyn A (1-13) $(30 \mu \mathrm{M})$ was also verified, and each fraction collected was incubated with this peptide in a water bath at $37^{\circ} \mathrm{C}$ for $90 \mathrm{~min}$. The analysis was subsequently observed on HPLC reverse phase chromatography (Prominence, Shimadzu, Kyoto, Japan) using a Shim-pack Restek C-18 column $(4.6 \times 250 \mathrm{~mm})$. Hydrolyses were analyzed by RP-HPLC, with $0.1 \%$ trifluoroacetic acid (TFA) in water as solvent $A$, and acetonitrile and solvent $A(9: 1)$ as solvent B. The used gradient was from $10 \%$ to $60 \%$ of solvent B in $20 \mathrm{~min}$, with UV detection at $214 \mathrm{~nm}$.

\subsection{Characterization of Isolated Proteases}

\subsubsection{SDS-PAGE—In Gel Digestion and Mass Spectrometry}

The active fractions of each purification step were analyzed by $12 \%$ polyacrylamide gel electrophoresis (SDS-PAGE) [45]. Samples $(2.0 \mu \mathrm{g})$ were solubilized in non-reducing sample buffer and silver-stained.

The purified proteases were subjected to an in-gel digestion with mass spectrometry grade trypsin from Sigma-Aldrich (St. Louis, MO, USA) [46]. The mixture was then desalted, concentrated 
and resuspended in $0.1 \%$ formic acid. Mass spectrometric analysis was performed by online liquid chromatography in an Easy-nLC Proxeon nanoHPLC system coupled to an LTQ-Orbitrap Velos (Thermo Fisher Scientific, Bremen, Germany) through a nanoelectrospray ion source. Raw data files were analyzed on Mascot Search Engine and on PEAKS Studio (version 8.0, Bioinformatics Solution, Waterloo, ON, Canada) against the library constructed with sequences deposited on UNIPROT/SwissProt, with a total of 554,567 sequences. A decoy database was also used to calculate false discovery rate (FDR) using the decoy-fusion method $[47,48]$. The search parameters were: trypsin cleavage specificity (max 1 missed cleavage); precursor mass tolerance set to $10 \mathrm{ppm}$; and a fragment ion mass tolerance of 0.5 Da. Regarding Post Translational Modifications (PTM), carbamidomethylation as fixed modification and oxidized methionine (Mp15.994915 Da) and deamidation (NQ) as variable modification were considered. The peptide sequences that resulted from MS/MS were analyzed in Peaks DB and the matched peptides were filtered by FDR $\leq 1 \%$, protein confidence score being $-10 \lg \mathrm{P} \geq 62$.

The deduced sequences of TsMS 3 and TsMS 4 transcripts from the gland of T. serrulatus [16] were aligned using NCBI Blast Tool.

\subsubsection{Biochemical Characterization: Effect of $\mathrm{pH}$, Cation Concentration and Temperature}

The Abz-GFLRRV-EDDnp substrate $(5 \mu \mathrm{M})$ was used to determine the influence of $\mathrm{pH}$, temperature and cations over the catalytic activity of metalloserrulase $3(90 \mathrm{ng})$ and metalloserrulase 4 (150 ng). In all assays, the final volume used was $100 \mu \mathrm{L}$ and hydrolyses were monitored on fluorimeter, as described on Section 5.3.2. Moreover, all results were obtained in triplicates and the mean and standard deviations $( \pm \mathrm{SD})$ between the tests were determined. The specific activities $(\mathrm{UF} / \mathrm{min} / \mu \mathrm{g})$ were obtained using the Grafit 5 software (Erithacus Software, West Sussex, UK).

For the study of $\mathrm{pH}$ influence over metalloserrulases activities, the following buffers were prepared, according to the recommendation of Stoll and Blanchard (1990): sodium phosphate ( $\mathrm{pH}$ 5.0-7.5), borax ( $\mathrm{pH} 7.6-9.2)$ and borax- $\mathrm{NaOH}(\mathrm{pH} 9.2-10)$, all at the final concentration of $50 \mathrm{mM}[49]$.

After the determination of the optimum $\mathrm{pH}$, the influence of monovalent and divalent cations on both peptidases activities was studied with Borax $\mathrm{pH}$ 8.5, in the presence of several types of mono and divalent cations as their chlorides $\left(\mathrm{Na}^{+}, \mathrm{K}^{+}, \mathrm{Li}^{+}, \mathrm{Mg}^{2+}, \mathrm{Ca}^{2+}\right)$, at final concentration of $50 \mathrm{mM}$. The rate of hydrolysis in the presence and absence of each ion was evaluated, identifying possible changes in TsMS 3 and TsMS 4 enzymatic activities.

The influence of temperature on metalloserrulases activities was also analyzed. For this, the activities of both peptidases were analyzed at temperatures between $22{ }^{\circ} \mathrm{C}$ and $42{ }^{\circ} \mathrm{C}$, on $5{ }^{\circ} \mathrm{C}$ intervals, using the best buffer indicated based on the results of the previous experiments (Borax $50 \mathrm{mM}, \mathrm{NaCl} 50 \mathrm{mM}, \mathrm{pH}$ 8.5).

\subsubsection{Analysis of The Cleavage Sites}

To determine the cleavage points of the Abz-GFLRRV-EDDnp substrate $(5 \mu \mathrm{M})$ obtained by metalloserrulase 3 and metalloserrulase 4 activities, $150 \mathrm{ng}$ of each protease were incubated in $50 \mathrm{mM}$ borax buffer $\mathrm{pH} 8.5$ for $15 \mathrm{~min}$ (final volume at $100 \mu \mathrm{L}$ ). Hydrolyses were monitored on fluorimeter Victor 3 (Perkin Elmer, MA, USA), as described in Section 5.3.2, and the cleavage was subsequently observed by RP-HPLC (same conditions as described on Section 5.3.3, with gradient modification varying from $30 \%$ to $80 \%$ of solvent B in $25 \mathrm{~min}$ ). The peaks were collected manually and then the cleavage points of each sample were determined in a MALDI TOF/TOF mass spectrometer (Axima Performance, Shimadzu Co, Kyoto, Japan) and the scissile bonds were deduced from the sequences of the substrate fragments. One microliter of each sample was co-crystallized with a supersaturated solution of $\alpha$-cyano-4-hydroxycinnamic acid matrix ( $50 \%$ acetonitrile/water $/ 0.1 \%$ TFA, $50 / 49.9 / 0.1, v / v / v)$, deposited on the sampler and dried at room temperature. The samples were analyzed and the spectra were acquired using the linear positive mode. 
For the neuropeptides cleavage points determination, metalloserrulases 3 and 4 (150 ng) were incubated with the natural substrates Dyn A (1-13) $(30 \mu \mathrm{M})$, neuropeptide $\mathrm{Y}(23.4 \mu \mathrm{M})$, peptide $\mathrm{YY}$ $(23.2 \mu \mathrm{M})$ and pancreatic polypeptide $(22.7 \mu \mathrm{M})$, for $6 \mathrm{~h}$ at $37^{\circ} \mathrm{C}$ in $50 \mathrm{mM}$ Borax buffer $50 \mathrm{mM} \mathrm{NaCl}$, $\mathrm{pH} 8.5$ (final volume at $100 \mu \mathrm{L}$ ). The cleavages were observed on reverse phase chromatography C-18 (Section 5.3.3) and the hydrolysis products were manually collected to be analyzed by mass spectrometry (Section 5.4.1). The de novo peptide sequences were obtained by software PEAKS Studio (version 8.0, Bioinformatics Solution, Waterloo, ON, Canada), with the following parameters: no specificity of the enzyme; precursor mass tolerance of $\pm 10 \mathrm{ppm}$ and an ion fragment mass tolerance of $\pm 0.5 \mathrm{Da}$; oxidized methionine $(\mathrm{M}+15.994915 \mathrm{Da})$ was defined as a variable modification. The identified peptides were classified according to their Average of Local Confidence (ALC) and those that had ALC $>80 \%$ were selected. The obtained cleavage points were, thus, utilized to study the primary specificity for substrate hydrolysis of TsMS 3 and TsMS 4. For this, amino acid corresponding to P3-P3' positions [50] were analyzed on the IceLogo tool [31], allowing frequency visualization of amino acid residues in each studied position.

\subsubsection{Kinetic Parameters for The Hydrolysis of FRET Substrates by TsMS 4}

Since TsMS 3 cleaved the FRETs substrates at two sites, these analyzes were performed only with TsMS 4. For determination of the Michaelis-Menten $\left(\mathrm{K}_{m}\right)$ and catalytic $\left(\mathrm{k}_{\text {cat }}\right)$ constants, sequential amounts of fluorescent substrate were used. The substrates analyzed were: Abz-GFLRRV-EDDnp, Abz-FLRRV-EDDnp and Abz-GFLRR-EDDnp, at concentrations of $2.5 \mu \mathrm{M}, 5 \mu \mathrm{M}, 10 \mu \mathrm{M}, 15 \mu \mathrm{M}$, $25 \mu \mathrm{M}, 50 \mu \mathrm{M}$ and $100 \mu \mathrm{M}$. The buffer used for metalloserrulase 4 was borax $\mathrm{pH}$ 8.5. Enzymatic activities were monitored on fluorimeter in the same conditions described on Section 5.3.2 for $30 \mathrm{~min}$. The standard hydrolysis conditions were strictly maintained for different substrates and the limit of substrate hydrolysis was $10 \%$ (initial rates of hydrolysis). The kinetic parameters were calculated by Michaelis-Menten equation using the Grafit 5 software (Erithacus Software, West Sussex, UK). For the $\mathrm{k}_{\text {cat }}\left(\mathrm{s}^{-1}\right)$ calculation, the maximum velocity $\left(V_{\max }\right)$ obtained in relative units of fluorescence per minute (UF/min) were converted to $\mu \mathrm{M}$ of substrate cleaved per minute $(\mu \mathrm{M} / \mathrm{min})$. The conversion was based on the total hydrolysis of $1 \mu \mathrm{M}$ Abz-FLRRV-EDDnp $(1440 \mathrm{UF}=1 \mu \mathrm{M})$. All experiments were performed in triplicates and represented as mean $\pm \mathrm{SD}$.

\subsection{Sera Neutralization Assays}

The potential of commercial antivenoms to neutralize metalloserrulases activities was evaluated by in vitro assay. For this, both metalloserrulases were pre-incubated with commercial antivenoms (scorpion or arachnidic antivenoms produced by the Butantan Institute, as described in Section 5.2) for $30 \mathrm{~min}$ in PBS buffer, $\mathrm{pH}$ 7.4. The concentrations (venom: antivenom ratio, in $\mu \mathrm{g}$ ) tested were: $1: 10 ; 1: 25 ; 1: 50 ; 1: 100 ; 1: 200 ; 1: 500$ and 1:1000. After the pre-incubation period, the substrate Abz-FLRRV-EDDnp $(5 \mu \mathrm{M})$ was added and the neutralization determined in Victor 3 fluorimeter, as described in Section 5.3.2. All experiments were performed in triplicates and represented as mean \pm SD.

Supplementary Materials: The following are available online at http:/ / www.mdpi.com/2072-6651/11/4/194/s1, Figure S1: Dynorphin A (1-13), $30 \mu \mathrm{M}$, cleavage profiles by (A) Fraction F3 and (B) Fraction F5. Each fraction was incubated with this peptide in a water bath at $37^{\circ} \mathrm{C}$ for $90 \mathrm{~min}$. Hydrolyses were visualized in the C-18 RP-HPLC system (Shimadzu) with UV detection at $214 \mathrm{~nm}$. (C) Each individual peak corresponded to hydrolysis products were collected and analyzed by LC-MS to determine the monoisotopic mass and, therefore, its sequence, Figure S2: Chromatographic profiles of the fluorescent substrate Abz-GFLRRV-EDDnp hydrolysis by metalloserrulase 3 (line 1, grey) and metalloserrulase 4 (line 2, black) in comparison to the integral peptide (line 3, dotted). The confirmation of each peak content was performed by mass spectrometry analysis.

Author Contributions: D.C.-C. planned and performed experiments, analyzed data and wrote the paper; C.C.F.d.S. analyzed the data, and wrote the paper; R.T.K. analyzed the data and wrote the paper; D.O.C.M. performed the experiments, and analyzed the data; D.C.P. performed the experiments, contributed reagents, and analyzed the data; A.K.K. analyzed the data, and wrote the paper; B.D. analyzed the data, and wrote the paper 
and F.V.P. planned the experiments, analyzed the data, contributed reagents, and wrote the paper. All authors reviewed the manuscript.

Funding: This study was supported by the Fundação de Amparo à Pesquisa do Estado de São Paulo (process 13/15343-0 and 15/15364-3), Coordenação de Aperfeiçoamento de Pessoal de Nível Superior (CAPES) and FINEP (grant numbe 01.12.0450.0). The funders had no role in study design, data collection and analysis, decision to publish, or preparation of the manuscript.

Acknowledgments: We would like to thank Ismael Feitosa Lima, from the Special Laboratory of Applied Toxinology/Center of Toxins, Immune-Response and Cell Signaling (CeTICS), Butantan Institute, for his expertise in mass spectrometry experiments.

Conflicts of Interest: The authors have declared that no competing interests exist. We confirm that the manuscript has been read and approved by all named authors and that there are no other persons who satisfied the criteria for authorship but are not listed. We further confirm that the order of authors listed in the manuscript has been approved by all of us.

\section{References}

1. SINAN. Acidente Por Animais Peçonhentos—Notificações Registradas No Sistema De Informação De Agravos De Notificação-Brasil. Available online: http:/ / tabnet.datasus.gov.br/cgi/deftohtm.exe?sinannet/ cnv/animaisbr.def;access (accessed on 10 October 2018).

2. Szilagyi-Zecchin, V.J.; Fernandes, A.L.; Castagna, C.; Voltolini, J. Abundance of scorpions Tityus serrulatus and Tityus bahiensis associated with climate in urban area (Scorpiones, Buthidae). Indian J. Arachnol. 2012, 1, 15-23.

3. Bucaretchi, F.; Baracat, E.C.; Nogueira, R.J.; Chaves, A.; Zambrone, F.A.; Fonseca, M.R.; Tourinho, F.S. A comparative study of severe scorpion envenomation in children caused by Tityus bahiensis and Tityus serrulatus. Rev. Inst. Med. Trop. Sao Paulo 1995, 37, 331-336. [CrossRef] [PubMed]

4. Bucaretchi, F.; Fernandes, L.C.; Fernandes, C.B.; Branco, M.M.; Prado, C.C.; Vieira, R.J.; De Capitani, E.M.; Hyslop, S. Clinical consequences of Tityus bahiensis and Tityus serrulatus scorpion stings in the region of Campinas, southeastern Brazil. Toxicon 2014, 89, 17-25. [CrossRef]

5. Casewell, N.R.; Wüster, W.; Vonk, F.J.; Harrison, R.A.; Fry, B.G. Complex cocktails: The evolutionary novelty of venoms. Trends Ecol. Evol. 2013, 28, 219-229. [CrossRef]

6. Waheed, H.; Moin, S.F.; Choudhary, M.I. Snake Venom: From Deadly Toxins to Life-saving Therapeutics. Curr. Med. Chem. 2017, 24, 1874-1891. [CrossRef]

7. Calvete, J.J.; Sanz, L.; Angulo, Y.; Lomonte, B.; Gutiérrez, J.M. Venoms, venomics, antivenomics. FEBS Lett. 2009, 583, 1736-1743. [CrossRef] [PubMed]

8. Paes Leme, A.F.; Prezoto, B.C.; Yamashiro, E.T.; Bertholim, L.; Tashima, A.K.; Klitzke, C.F.; Camargo, A.C.; Serrano, S.M. Bothrops protease A, a unique highly glycosylated serine proteinase, is a potent, specific fibrinogenolytic agent. J. Thromb. Haemost. 2008, 6, 1363-1372. [CrossRef] [PubMed]

9. White, J. Snake venoms and coagulopathy. Toxicon 2005, 45, 951-967. [CrossRef]

10. Cologna, C.T.; Marcussi, S.; Giglio, J.R.; Soares, A.M.; Arantes, E.C. Tityus serrulatus scorpion venom and toxins: An overview. Protein Pept. Lett. 2009, 16, 920-932. [CrossRef] [PubMed]

11. Morgenstern, D.; Rohde, B.H.; King, G.F.; Tal, T.; Sher, D.; Zlotkin, E. The tale of a resting gland: Transcriptome of a replete venom gland from the scorpion Hottentotta judaicus. Toxicon 2011, 57, 695-703. [CrossRef] [PubMed]

12. Alvarenga, É.R.; Mendes, T.M.; Magalhaes, B.F.; Siqueira, F.F.; Dantas, A.E.; Barroca, T.M.; Horta, C.C.; Kalapothakis, E. Transcriptome analysis of the Tityus serrulatus scorpion venom gland. Open J. Genet. 2012, 2, 210. [CrossRef]

13. Almeida, D.D.; Scortecci, K.C.; Kobashi, L.S.; Agnez-Lima, L.F.; Medeiros, S.R.; Silva-Junior, A.A.; Junqueira-de-Azevedo, I.e.L.; Fernandes-Pedrosa, M.e.F. Profiling the resting venom gland of the scorpion Tityus stigmurus through a transcriptomic survey. BMC Genom. 2012, 13, 362. [CrossRef] [PubMed]

14. de Oliveira, U.C.; Candido, D.M.; Dorce, V.A.; Junqueira-de-Azevedo, I.e.L. The transcriptome recipe for the venom cocktail of Tityus bahiensis scorpion. Toxicon 2015, 95, 52-61. [CrossRef] [PubMed] 
15. de Oliveira, U.C.; Nishiyama, M.Y.; Dos Santos, M.B.V.; Santos-da-Silva, A.P.; Chalkidis, H.M.; Souza-Imberg, A.; Candido, D.M.; Yamanouye, N.; Dorce, V.A.C.; Junqueira-de-Azevedo, I.L.M. Proteomic endorsed transcriptomic profiles of venom glands from Tityus obscurus and T. serrulatus scorpions. PLoS ONE 2018, 13, e0193739. [CrossRef]

16. Carmo, A.O.; Oliveira-Mendes, B.B.; Horta, C.C.; Magalhães, B.F.; Dantas, A.E.; Chaves, L.M.; Chávez-Olórtegui, C.; Kalapothakis, E. Molecular and functional characterization of metalloserrulases, new metalloproteases from the Tityus serrulatus venom gland. Toxicon 2014, 90, 45-55. [CrossRef]

17. Hooper, N.M. Families of zinc metalloproteases. FEBS Lett. 1994, 354, 1-6. [CrossRef]

18. Fletcher, P.L.; Fletcher, M.D.; Weninger, K.; Anderson, T.E.; Martin, B.M. Vesicle-associated membrane protein (VAMP) cleavage by a new metalloprotease from the Brazilian scorpion Tityus serrulatus. J. Biol. Chem. 2010, 285, 7405-7416. [CrossRef] [PubMed]

19. Zornetta, I.; Scorzeto, M.; Mendes Dos Reis, P.V.; De Lima, M.E.; Montecucco, C.; Megighian, A.; Rossetto, O. Electrophysiological Characterization of the Antarease Metalloprotease from Tityus serrulatus Venom. Toxins 2017, 9, 81. [CrossRef] [PubMed]

20. Ortiz, E.; Rendón-Anaya, M.; Rego, S.C.; Schwartz, E.F.; Possani, L.D. Antarease-like Zn-metalloproteases are ubiquitous in the venom of different scorpion genera. Biochim. Biophys. Acta 2014, 1840, 1738-1746. [CrossRef]

21. Cajado-Carvalho, D.; Kuniyoshi, A.K.; Duzzi, B.; Iwai, L.K.; Oliveira, Ú.; Junqueira de Azevedo, I.L.; Kodama, R.T.; Portaro, F.V. Insights into the Hypertensive Effects of Tityus serrulatus Scorpion Venom: Purification of an Angiotensin-Converting Enzyme-Like Peptidase. Toxins 2016, 8, 348. [CrossRef] [PubMed]

22. Verano-Braga, T.; Dutra, A.A.; León, I.R.; Melo-Braga, M.N.; Roepstorff, P.; Pimenta, A.M.; Kjeldsen, F. Moving pieces in a venomic puzzle: Unveiling post-translationally modified toxins from Tityus serrulatus. J. Proteome Res. 2013, 12, 3460-3470. [CrossRef]

23. Venancio, E.J.; Portaro, F.C.; Kuniyoshi, A.K.; Carvalho, D.C.; Pidde-Queiroz, G.; Tambourgi, D.V. Enzymatic properties of venoms from Brazilian scorpions of Tityus genus and the neutralisation potential of therapeutical antivenoms. Toxicon 2013, 69, 180-190. [CrossRef] [PubMed]

24. Cajado Carvalho, D.; Kuniyoshi, A.K.; Kodama, R.T.; Oliveira, A.K.; Serrano, S.M.; Tambourgi, D.V.; Portaro, F.V. Neuropeptide Y family-degrading metallopeptidases in the Tityus serrulatus venom partially blocked by commercial antivenoms. Toxicol. Sci. 2014, 142, 418-426. [CrossRef] [PubMed]

25. Stein, C.; Schäfer, M.; Machelska, H. Attacking pain at its source: New perspectives on opioids. Nat. Med. 2003, 9, 1003-1008. [CrossRef]

26. Tan, C.M.J.; Green, P.; Tapoulal, N.; Lewandowski, A.J.; Leeson, P.; Herring, N. The Role of Neuropeptide Y in Cardiovascular Health and Disease. Front. Physiol. 2018, 9, 1281. [CrossRef]

27. Spinazzi, R.; Andreis, P.G.; Nussdorfer, G.G. Neuropeptide-Y and Y-receptors in the autocrine-paracrine regulation of adrenal gland under physiological and pathophysiological conditions (Review). Int. J. Mol. Med. 2005, 15, 3-13. [CrossRef] [PubMed]

28. Nussdorfer, G.G.; Gottardo, G. Neuropeptide-Y family of peptides in the autocrine-paracrine regulation of adrenocortical function. Horm. Metab. Res. 1998, 30, 368-373. [CrossRef]

29. Portaro, F.C.; Santos, A.B.; Cezari, M.H.; Juliano, M.A.; Juliano, L.; Carmona, E. Probing the specificity of cysteine proteinases at subsites remote from the active site: Analysis of P4, P3, P2' and P3' variations in extended substrates. Biochem. J. 2000, 347 Pt 1, 123-129. [CrossRef]

30. Grundemar, L.; Håkanson, R. Effects of various neuropeptide $Y$ / peptide $Y Y$ fragments on electrically-evoked contractions of the rat vas deferens. Br. J. Pharmacol. 1990, 100, 190-192. [CrossRef] [PubMed]

31. Colaert, N.; Helsens, K.; Martens, L.; Vandekerckhove, J.; Gevaert, K. Improved visualization of protein consensus sequences by iceLogo. Nat. Methods 2009, 6, 786-787. [CrossRef]

32. Tallant, C.; García-Castellanos, R.; Baumann, U.; Gomis-Rüth, F.X. On the relevance of the Met-turn methionine in metzincins. J. Biol. Chem. 2010, 285, 13951-13957. [CrossRef]

33. Dudev, T.; Lim, C. Metal selectivity in metalloproteins: Zn2+ vs. Mg2+. J. Phys. Chem. B 2001, 105, 4446-4452. [CrossRef]

34. Wise, R.J.; Barr, P.J.; Wong, P.A.; Kiefer, M.C.; Brake, A.J.; Kaufman, R.J. Expression of a human proprotein processing enzyme: Correct cleavage of the von Willebrand factor precursor at a paired basic amino acid site. Proc. Natl. Acad. Sci. USA 1990, 87, 9378-9382. [CrossRef] 
35. Langenegger, N.; Koua, D.; Schürch, S.; Heller, M.; Nentwig, W.; Kuhn-Nentwig, L. Identification of a precursor processing protease from the spider. J. Biol. Chem. 2018, 293, 2079-2090. [CrossRef]

36. Saraf, R.; Mahmood, F.; Amir, R.; Matyal, R. Neuropeptide $\mathrm{Y}$ is an angiogenic factor in cardiovascular regeneration. Eur. J. Pharmacol. 2016, 776, 64-70. [CrossRef] [PubMed]

37. Śliwińska-Mossoń, M.; Marek, G.; Milnerowicz, H. The role of pancreatic polypeptide in pancreatic diseases. Adv. Clin. Exp. Med. 2017, 26, 1447-1455. [CrossRef] [PubMed]

38. Inyushkin, A.N. Effects of leucine-enkephalin on potassium currents in neurons in the rat respiratory center in vitro. Neurosci. Behav. Physiol. 2007, 37, 739-746. [CrossRef] [PubMed]

39. Tsunoo, A.; Yoshii, M.; Narahashi, T. Block of calcium channels by enkephalin and somatostatin in neuroblastoma-glioma hybrid NG108-15 cells. Proc. Natl. Acad. Sci. USA 1986, 83, 9832-9836. [CrossRef] [PubMed]

40. Cabot, P.J.; Carter, L.; Schäfer, M.; Stein, C. Methionine-enkephalin-and Dynorphin A-release from immune cells and control of inflammatory pain. Pain 2001, 93, 207-212. [CrossRef]

41. Zoccal, K.F.; Sorgi, C.A.; Hori, J.I.; Paula-Silva, F.W.; Arantes, E.C.; Serezani, C.H.; Zamboni, D.S.; Faccioli, L.H. Opposing roles of LTB4 and PGE2 in regulating the inflammasome-dependent scorpion venom-induced mortality. Nat. Commun. 2016, 7, 10760. [CrossRef] [PubMed]

42. Trevisan-Silva, D.; Gremski, L.H.; Chaim, O.M.; da Silveira, R.B.; Meissner, G.O.; Mangili, O.C.; Barbaro, K.C.; Gremski, W.; Veiga, S.S.; Senff-Ribeiro, A. Astacin-like metalloproteases are a gene family of toxins present in the venom of different species of the brown spider (genus Loxosceles). Biochimie 2010, 92, 21-32. [CrossRef] [PubMed]

43. Cajado-Carvalho, D.; Galvão, J.; Kuniyoshi, A.K.; Carneiro, P.D.S.; Paes Leme, A.F.; Pauletti, B.A.; Marengo, E.B.; Portaro, F.V. Tityus serrulatus Scorpion Venom: In Vitro Tests and Their Correlation with In Vivo Lethal Dose Assay. Toxins 2017, 9, 380. [CrossRef] [PubMed]

44. Hui Wen, F.; Monteiro, W.M.; Moura da Silva, A.M.; Tambourgi, D.V.; Mendonça da Silva, I.; Sampaio, V.S.; dos Santos, M.C.; Sachett, J.; Ferreira, L.C.; Kalil, J.; et al. Snakebites and scorpion stings in the Brazilian Amazon: Identifying research priorities for a largely neglected problem. PLoS Negl. Trop. Dis. 2015, 9, e0003701. [CrossRef] [PubMed]

45. Laemmli, U.K. Cleavage of structural proteins during the assembly of the head of bacteriophage T4. Nature 1970, 227, 680-685. [CrossRef] [PubMed]

46. Shevchenko, A.; Tomas, H.; Havlis, J.; Olsen, J.V.; Mann, M. In-gel digestion for mass spectrometric characterization of proteins and proteomes. Nat. Protoc. 2006, 1, 2856-2860. [CrossRef]

47. Ma, B.; Zhang, K.; Hendrie, C.; Liang, C.; Li, M.; Doherty-Kirby, A.; Lajoie, G. PEAKS: Powerful software for peptide de novo sequencing by tandem mass spectrometry. Rapid Commun. Mass Spectrom. 2003, 17, 2337-2342. [CrossRef] [PubMed]

48. Zhang, J.; Xin, L.; Shan, B.; Chen, W.; Xie, M.; Yuen, D.; Zhang, W.; Zhang, Z.; Lajoie, G.A.; Ma, B. PEAKS DB: De novo sequencing assisted database search for sensitive and accurate peptide identification. Mol. Cell Proteom. 2012, 11, M111.010587. [CrossRef] [PubMed]

49. Stoll, V.S.; Blanchard, J.S. Buffers: Principles and practice. Methods Enzymol. 1990, 182, 24-38.

50. Schechter, I.; Berger, A. On the size of the active site in proteases. I. Papain. Biochem. Biophys. Res. Commun. 1967, 27, 157-162. [CrossRef]

(C) 2019 by the authors. Licensee MDPI, Basel, Switzerland. This article is an open access article distributed under the terms and conditions of the Creative Commons Attribution (CC BY) license (http://creativecommons.org/licenses/by/4.0/). 